\title{
Transcriptional Regulation of Gene Expression by microRNAs as Endogenous Decoys of Transcription Factors
}

\author{
Chunhui Cui $^{\mathrm{a}}$ Jinlong Yu Shuxin Huang ${ }^{\mathrm{b}}$ Huiquan Zhu ${ }^{\mathrm{a}}$ Zonghai Huang ${ }^{\mathrm{a}}$ \\ aDepartment of General Surgery, Zhujiang Hospital, Southern Medical University, ${ }^{b}$ Department of \\ Ophthalmology, Zhujiang Hospital, Southern Medical University, Guangzhou, China
}

\section{Key Words}

Transcriptional regulation - Transcription factors - miRNAs - Precursor miRNAs - Decoy oligonucleotides $\cdot \mathrm{miR}-939 \cdot \mathrm{miR}-276 \mathrm{a}$

\begin{abstract}
Background/Aims: MicroRNAs (miRNAs) are known to produce post-transcriptional repression of gene expression. In light of the ability of decoy oligodeocynucleotides (ODNs) to sequestrate transcription factors (TFs) and the similar double-stranded structure between decoy ODNs and miRNAs, we proposed that miRNAs might act as endogenous decoy molecules to produce transcriptional regulation of gene expression. Methods: Quantitative real-time RT-PCR analysis was used to measure the changes of miRNA and mRNA expression. Luciferase reporter gene activity assay was used to investigate the functional interaction between miRNAs and TFs. Electrophoresis mobility shift assay (EMSA) and modified chromatin immunoprecipitation assay (ChIP) were utilized to investigate the physical interactions between miRNAs and TFs. MTT cell viability assay and cellular DNA fragmentation ELISA were used to study apoptotic cell death. Results: We presented here that miRNAs could regulate, either negatively or positively, gene expression at the transcriptional level through its decoy-like actions and this mechanism operates under physiological conditions to produce cellular functions. We identified the putative cis-elements for transcriptional factors NF-KB and NFAT in the mature miR-939 and miR-376a, respectively. We experimentally established the ability of these miRNAs to physically bind their respective target TFs, using EMSA and ChIP methods. We then utilized the luciferase reporter gene assay to characterize the specific regulation of luciferase gene activities by miR-939/pre-miR-939:NF-kB or miR-376a/pre-miR$376 a$ :NFAT interactions. Moreover, miR-939 and miR-376a produced transcriptional regulation of endogenous genes $\mathrm{Bcl}-\mathrm{xL}$ and $\mathrm{FasL} / m i R-26$ that are the transcriptional targets for NF-kB and NFAT, respectively, but are not post-transcriptional targets for these two miRNAs. Finally, interference of these miRNAs with NF-KB and NFAT demonstrated clear phenotypes at the cellular level as manifested by the regulation of neuroblastoma cell death by miR-939 and miR-376a. Conclusion: Our study identified a novel non-canonical mechanism of miRNAs and suggests that when considering the cellular function of miRNAs the decoy-like mechanism for transcriptional regulation (activation or repression) should be taken into account.
\end{abstract}

Copyright $\odot 2014$ S. Karger AG, Basel

Dr. Zonghai Huang, MD 
Cui et al.: A Novel Mechanism of miRNAs in Gene Regulation

\section{Introduction}

Transcription factors (TFs) are a class of nuclear proteins that play a critical role in gene regulation by exerting either a positive or a negative effect on gene expression. These regulatory proteins interact with their target genes through binding specific sequences in the promoter regions, either activating or repressing the transcription of these genes. The binding sequences are generally 6 10 bp in length that bears unique sequence information for recognition by specific TFs, and the binding sites for a single TF may vary by several base pairs among the promoter regions of different genes. Thus, they are generally described as common motifs or consensus binding sites or cis-acting promoter elements (cis-elements). Through regulating gene expression, TFs virtually control all aspects of cellular functions, including cell differentiation and organogenesis, cell growth and death, and cell signaling transduction. TFs comprise $6 \%$ of the human genome ranking the second position for their abundance with increasing number of factors and their binding sites being characterized and have recently been considered a new class of candidate targets for drug discovery [1]. TFs can recognize short target sequences even in the absence of surrounding genomic DNA structures, and this property provides an opportunity for interfering the actions of TFs by using the so-called decoy oligodeoxynucleotides (decoy ODN) that was first introduced by Bielinska and coworkers [2]. The decoy ODN technology involves synthetic doublestranded ODN of around $20 \mathrm{bp}$ long containing a cis-element with high affinity for a target $\mathrm{TF}$, which can bind the TF after being introduced into cells and attenuate authentic cistrans interaction, leading to removal of trans-factors from the endogenous cis-element with subsequent modulation of gene expression $[3,4]$. The potential for therapeutic applications of decoy ODNs has been well evidenced by experimental investigations and clinical trials [5-8].

On the other hand, in addition to the transcriptional regulation by TFs, gene expression is also regulated post-transcriptionally by microRNAs (miRNAs), a large, ubiquitous class of endogenous noncoding regulatory mRNAs. These small molecules are processed initially in the nucleus by the RNase III enzyme Drosha to form the precursor miRNAs (pre-miRNAs) with characteristic stem-loop or hairpin structures of 60 100 bp in length and subsequently processed in the cytoplasm by another RNase III enzyme Dicer to form the double-stranded mature miRNAs of $\sim 22 \mathrm{bp}$ in length. This biogenic pathway is utilized by intergenic miRNAs and alternatively, pre-miRNAs can be formed through debranching of stem-loop structures contained within the introns of genes (intronic miRNAs), which is subsequently cropped by Dicer to generate mature miRNAs. Mature miRNAs can interact with Argonaute protein to form the RNA-induced silencing complex (RISC) and one of the strand of the mature miRNA can then guide the RISC to their target mRNAs by a partial base-paring mechanism, most favorably to the 3'-untranslated region (3'UTR) with the other strand being degraded. In order for a miRNA to give rise to functional consequences, its $5^{\prime}$-end 2 to 8 nts (the socalled 'seed site') must have exact complementarity to the target mRNA and the rest of the sequence may have partial complementarity $[9,10]$. A miRNA can either inhibit translation or induce degradation of its target mRNA, depending upon the overall degree of complementarity of the binding site, number of binding sites, and the accessibility of the bindings sites (determined by free energy states). A recent study indicates that miRNAs can also act as translational activator of genes under certain circumstances when AU-rich elements and miRNA target sites coexist at proximity in the target mRNA and when the cells are in the state of cell-cycle arrest [11]. MiRNAs have also been increasingly implicated in the control of various biological processes, including cell differentiation, cell proliferation, development, and apoptosis, and many pathological processes such as cancer, Alzheimer's disease, cardiovascular disease, etc $[12,13]$. Also important to note is that miRNAs are in general abundantly expressed molecules, and the number of miRNA species in mammalians has reached nearly 700, and the number is still increasing and might be as many as thousands according to computational prediction [14]. 
In our pilot study on miR-939 and miR-376a that have been documented to regulate human inducible nitric oxide synthase expression in hepatocytes [15] and invasiveness of glioblastoma cells [16], respectively, we observed results that could hardly be explained based on miRNA actions; instead, they would be better understood by TF mechanism. miR939 downregulated B-cell lymphoma-extra large (Bcl-xL) and miR-376a upregulated miR-26, neither of which are its target gene. Bcl-xL is supposedly transactivated by nuclear factor kappaB $(\mathrm{NF}-\mathrm{\kappa B})[17,18]$ and $m i R-26$ is transcriptionally repressed by nuclear factor of activated T cells (NFAT) [19]. In light of the ability of decoy ODNs to sequestrate TFs and the similar double-stranded structure between decoy ODNs and miRNAs, as well as the well-known ability of RNAs (besides DNA) to interact with proteins, we hypothesized that miRNAs might act as endogenous decoy molecules to produce transcriptional regulation of gene expression. Here we present the evidence for this notion by demonstrating the ability of miR-939 and miR-376a to mimic the action of decoy molecules for NF- $\kappa B$ and NFAT, respectively, thereby revealing a novel property of miRNA function.

\section{Materials and Methods}

Synthesis of miRNAs and anti-miRNA antisense inhibitors

Wild-type miR-376a and miR-939, mutant miR-376a and miR-939, antisense oligonucleotides inhibitors to $m i R-939, m i R-376 a, m i R-1$ and $m i R-21$, and mismatched inhibitors (Fig. 1) were synthesized by Integrated DNA Technologies, Inc. (IDT).

Construction of NF- $\kappa$ B and NFAT promoter-luciferase fusion plasmids

A 1.2-kb segment of the proximal Bcl-xL promoter containing NF-kB binding sites [17] and HindIII and SpeI endonuclease sites was PCR synthesized. The segment was digested with HindIII and SpeI, and subsequently ligated into HindIII and SpeI sites in the luciferase-containing PGL3-Basic (Promega) vector, as described elsewhere [20]. The integrity and orientation of all constructs were confirmed by restriction endonuclease analysis and DNA sequencing. PCR-based mutagenesis with nucleotide replacement to the NF- $\mathrm{kB}$ binding core motif (5'-GGGACTTTC-3' for wild-type and 5'-GttcCTTTC-3' for mutant) was carried out. The mutant construct was subcloned into PGL3-Basic vector. For NFAT, a 300-bp cDNA fragment spanning the NFAT binding motif GGGCGGAAA (located at -244 to -253 from the translation start site) [21] and another fragment carrying mutation to the NFAT binding motif GGGCttcAA were PCR synthesized and separately subcloned into PGL3-Basic vector. These promoter elements were used to drive luciferase gene expression to generate reporter gene activities.

\section{Preparation of decoy ODNS}

We followed the methods described by Gao et al [20] for preparing decoy ODNs. Briefly, singlestranded phosphorothioate decoy oligodeoxynucleotides (ODNs) were synthesized by IDT incorporation (Coralville, IA). The ODNs were washed in 70\% ethanol, dried and dissolved in sterilized Tris-EDTA buffer (10 mM Tris + $1 \mathrm{mM}$ EDTA). The supernatant was purified using Micro Bio-spin30 columns (BioRad, Hercules, CA) and quantified by spectrophotometry. The double-stranded decoy ODNs were then prepared by annealing complementary single stranded ODNs (Fig. 1) by heating to $95^{\circ} \mathrm{C}$ for $10 \mathrm{~min}$ followed by cooling to room temperature slowly over $2 \mathrm{~h}$. Stocks of decoy ODNs were prepared at a concentration of 50 $\mathrm{mM}$ in saline. The sequence of NF- $\mathrm{kB}$ decoy ODN is: sense 5'-GAGUGGGACTTTCCCAGCGTG-3' and antisense 5'-CTCGCTGGGAAAGTCCCACTC-3', and that of NFAT is: sense 5'-CGCCCAAAGAGGAAAATTTGTTTCATA-3' and antisense 5'-TATGAAACAAATTTTCCTCTTTGGGCG-3'. (The consensus binding sites are bold and underlined). The efficacy of the decoy ODNs has been previously verified [18].

\section{Cell culture}

Human embryonic kidney cell line HEK293 cells and rat ventricular cell line H9c2 cells were grown in DMEM. Human neuroblastoma cell line SH-SY5Y cells were grown DMEM/F12K medium, supplemented with $10 \%$ fetal bovine serum, $2 \mathrm{mM}$ glutamine, $100 \mathrm{U} / \mathrm{ml}$ penicillin, and $100 \mathrm{mg} / \mathrm{ml}$ streptomycin. The cells and media were purchased from ATCC (Manassas, VA). 


\section{SH-SY5Y cell nuclear protein extract}

SH-SY5Y cells were maintained at $37^{\circ} \mathrm{C}$ in a humidified $5 \% \mathrm{CO} 2$ to electrophoresis on Novex Retardation Gel (6\% polyacrylamide) (Invitrogen) and electroblotted to a positively charged nylon membrane (Roche). The blots were visualized by an enzyme immunoassay using anti-digoxigenin-AP, Fab fragments, and the chemiluminescent substrate CSPD (Tropix) and subsequently were exposed to $\mathrm{x}$-ray films.

\section{Transfection procedures}

Cells were transfected with $1 \mu \mathrm{g}$ miRNA and/or miRNA inhibitors, and negative control constructs with lipofectamine 2000 (Invitrogen), according to the manufacturer's instructions. Forty-eight hours after transfection, cells were used for luciferase assay or were collected for total RNA or protein purification.

For NF-KB and NFAT decoy ODNs, cells were washed with serum-free medium once and then incubated with $50 \mu$ l fresh fetal bovine serum (FBS)-free medium. The cells were transfected with the decoy ODNs using Lipofectamine 2000 (Invitrogen, Carlsbad, CA). For viability study, cells were seeded in 96-well tissue culture plates. At 50\% confluence, the cells were washed with serum-free medium once and then incubated with $50 \mu \mathrm{l}$ fresh fetal bovine serum (FBS)-free medium. Decoy ODNs and lipofectamine ( $0.25 \mu \mathrm{l})$ were separately mixed with $25 \mu \mathrm{l}$ of Opti-MEM ${ }^{\circledR}$ I Reduced Serum Medium (Gibco, Grand Island, NY) for 5 $\mathrm{min}$. Then the two mixtures were combined and incubated for $20 \mathrm{~min}$ at RT. The lipofectamine:decoy ODNs mixture was added dropwise to the cells and incubated at $37^{\circ} \mathrm{C}$ for $5 \mathrm{~h}$. Subsequently, $25 \mu$ fresh medium containing 30\% FBS was added to the well and the cells were maintained in the culture until use, either for cell growth assays or for RNA extraction.

\section{Luciferase activity assay}

HEK293 cells were transfected with $1 \mu$ g PGL3-target DNA (firefly luciferase vector) and $0.1 \mu \mathrm{g}$ PRLTK (TK-driven Renilla luciferase expression vector) with lipofectamine 2000. Following transfection (48 h), luciferase activities were measured with a dual luciferase reporter assay kit (Promega) on a luminometer (Lumat LB9507). For all experiments, transfection took place $24 \mathrm{~h}$ after starvation of cells in serum-free medium.

\section{Quantitative real-time RT-PCR analysis}

Total RNA samples were extracted from cultured cells using Trizol reagents and treated with DNase I. Single strand cDNA was reverse transcribed from total RNA using random primer under standard conditions with the High Capacity cDNA reverse transcription kit (Applied Biosystems, Foster City, CA, USA). Quantitative real-time PCR with total cDNA was performed with SYBR Green Master Mix Real-Time Core Reagents on an ABI 7500 (Applied Biosystems) according to the manufacturer's instructions. We determined the appropriate cycle threshold $(\mathrm{Ct})$ using the automatic baseline determination feature. Fold variations in expression of a miRNA or mRNA between RNA samples were calculated. We used expression level of GAPDH as an internal control. All samples were tested in triplicate, and the average values were used for quantification.

\section{Electrophoresis mobility shift assay (EMSA)}

miR-376a, miR-939, and NF- $\mathrm{BB}$ and NFAT decoy ODNs were labeled by mixing $4 \mu \mathrm{l}(50 \mathrm{ng})$ annealed decoy ODNs with $4 \mu \mathrm{l}$ T4 kinase buffer (5×), $1 \mu \mathrm{l}$ DTT (0.1 M), $6 \mu \mathrm{l} \gamma$-p32-ATP, $3 \mu \mathrm{l} \mathrm{ddHB}{ }_{2 \mathrm{~B}} \mathrm{O}$ and $2 \mu \mathrm{l} \mathrm{T} 4$ kinase. The sample was incubated at $37^{\circ} \mathrm{C}$ for $1 \mathrm{~h}$ and then $80 \mu \mathrm{TE}(10 \mathrm{mM}$ Tris-HCL pH 8.0) was added to complete the reaction. The sample was then loaded into the G-25 column and centrifuged at $7000 \mathrm{~g}$ for $2 \mathrm{~min}$. Binding reactions were carried out at room temperature for $15 \mathrm{~min}$ in a buffer containing $2 \mu \mathrm{g}$ nuclear extract sample from SH-SY5Y human neuroblastoma cells (EMD Millipore Corporation, Billerica, MA, USA) in $10 \mu \mathrm{HB}_{2 \mathrm{~B}} \mathrm{O}$ and $8 \mu \mathrm{l}$ of master mix (12×) containing $1 \mathrm{M}$ Tris-HCl (pH7.5), 0.5 M EDTA, $5 \mathrm{M}$ $\mathrm{NaCl}, 1 \mathrm{M}$ DTT, $50 \%$ glycerol, $100 \mu \mathrm{g} / \mu \mathrm{l} \mathrm{BSA}$, and $1 \mu \mathrm{g} / \mu \mathrm{l}$ poly dIdC. For super shift experiment, antibodies $(1 \mu \mathrm{g})$ were included in the reaction, and for competition experiments, unlabeled constructs in 100 -fold excess of the labeled ones were added in the binding reactions. Then, $2 \mu \mathrm{l}(100,000 \mathrm{cpm} / \mu \mathrm{l}) \mathrm{P}^{32 \mathrm{P}} \mathrm{P}$-labeled decoy ODNs were added to the reaction and incubated for another $15 \mathrm{~min}$ at RT, followed by addition of $2 \mu \mathrm{l}$ loading dye. DNA-protein complexes were separated by non-denaturing polyacrylamide gel $(7.5 \%$ in $0.4 \times$ TBE) electrophoresis. Gels were dried and analyzed with Typhoon image system (Amersham Bioscience) and quantified with ImageQuant software (Version 5.2). 


\section{Modified chromatin immunoprecipitation assay}

ChIP assays were conducted with the EZ ChIP kit according to the manufacturer's instructions (Upstate Cell Signaling Solutions, Lake Placid, NY) which were essentially the same as described previously by other laboratory [22]. Briefly, SH-SY5Y cells were were grown to subconfluency, washed and fixed in 1\% formaldehyde for $10 \mathrm{~min}$ to crosslink nucleoprotein complexes and scraped in phosphate buffered saline containing protease inhibitor cocktail. Pelleted cells were then lysed and sonicated in detergent lysis buffer. Sheared DNA-protein complexes or miRNA-protein complexes were immunoprecipitated by incubating overnight the lysates with $2 \mu \mathrm{g}$ antibodies against NF-кB, NFAT, or lamin A (as a control; all from Santa Cruz Biotech). Protein A/G Plus beads (Santa Cruz Biotech) were used, and after extensive washing, crosslinks were removed at $65^{\circ} \mathrm{C}$ over overnight in an elution buffer ( $1 \%$ SDS, $0.1 \mathrm{M} \mathrm{NaHCO}_{3}$ ).

For detection of DNA-protein complexes, the DNA was isolated using the QIAquick PCR purification kit (Qiagen) and the presence of NF- $\kappa B$ or NFAT in the promoter region of the Bcl-xL gene or the FasL gene promoter was verified by real-time RT-PCR amplification using $10 \%$ of purified DNA. The PCR products were analysed by gel electrophoreses on an $8 \%$ non-denaturing polyacrylamide gel and subsequent ethidium bromide staining. To verify the specificity of DNA-protein interaction, cells were treated with miR-939, miR$376 a$ or their mutant constructs before fixation. The primer pair for Bcl-xL is: forward 5'-GCAGGCGACGAG TTTGAACT-3' and reverse 5'-CTCGGCTGCTG ATTGTTC-3' with an expected PCR product of 87 bp; for FasL: forward 5'-GTCTACCAGCCAGATGCACACAGC-3' and reverse 5'-GTACCTCATGACTGCCTCTGTGGG-3' with an expected PCR product of $72 \mathrm{bp}$.

For detection of miRNA-protein complexes, precursor miRNA (pre-miRNAs) samples were isolated using the NucleoSpin ${ }^{\circledR}$ miRNA Kit (Clontech Laboratories, Inc, Mountain View, CA, USA), according to manufacturer's instructions. The presence of NF- $\kappa$ B or NFAT in the pre-miR-939 or pre-miR-376a was verified by real-time RT-PCR amplification using $1 \mu \mathrm{g}$ of purified RNA. The PCR products were analysed by gel electrophoreses on a 10\% denaturing polyacrylamide gel and subsequent ethidium bromide staining. The primer pair for has-pre-miR-939 is: forward 5'-UGUGGGCAGGGCCCUGGGGAG-3' and reverse 5'-UACAUCGCGGUCAGACACUG-3' with an expected PCR product of $87 \mathrm{bp}$; for has-pre-miR-376a: forward 5'-CGGCUAAAAGGUAGAUUCUCC-3' and reverse 5'-GCGAAAACGUGGAUUUUCCUC-3' with an expected PCR product of $72 \mathrm{bp}$.

\section{MTT cell viability assay}

MTT Cell Proliferation/Viability Assay kit (R\&D Systems China Co. Ltd.) was used assess cell viability according to the manufacturer's instruction. MTT was added directly to the culture medium and was reduced by metabolically active cells to insoluble purple formazan dye crystals. The absorbance of the sample was read directly in the wells at an optimal wavelength of $570 \mathrm{~nm}$ using a microplate reader (GloMax®)-96 Microplate Luminometer, Promega).

\section{Cellular DNA Fragmentation ELISA}

Cell apoptosis was assessed by measuring DNA fragmentation using cellular DNA fragmentation ELISA kit (Roche Applied Sciences, Cat\#: 11585045001) according to the manufacturer's protocol. Culture supernatant and cytoplasmic fractions (lysates) of cells with DNA were metabolically prelabeled with BrdU. The absorbance of the sample was read directly in the wells at an optimal wavelength of $405 \mathrm{~nm}$ using a microplate reader (GloMax®-96 Microplate Luminometer, Promega).

\section{Data analysis}

Group data are expressed as mean \pm SEM. Statistical comparisons among multiple groups were performed by analysis of variance (ANOVA). If significant effects were indicated by ANOVA, a $t$-test with Bonferroni correction or a Dunnett's test was used to evaluate the significance of differences between individual means. Otherwise, baseline and drug data were compared by paired Student's $t$-test and agematched comparisons between control and drug were done by unpaired Student's $t$-test. Group comparisons for AF incidence were performed using $\chi^{2}$-test. A two-tailed $p<0.05$ was taken to indicate a statistically significant difference. Cis-elements for transcription factor binding sites were analyzed with MatInspector V2.2 (Genomatix). 


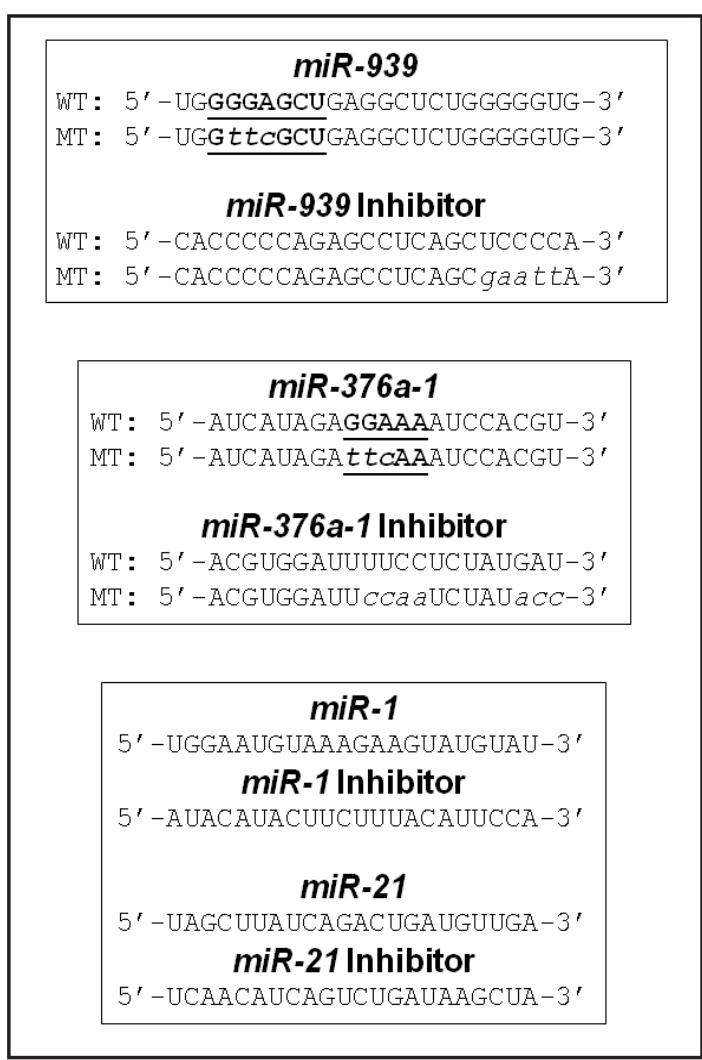

Fig. 1. Sequences of wild-type miR-376a and $m i R$ 939, mutant miR-376a and miR-939, antisense oligonucleotides inhibitors to miR-939, miR-376a, miR-1 and $m i R-21$, and mismatched inhibitors. Bold and underlined letters indicate the core binding site for NF- $\kappa \mathrm{B}$ in miR-939 which overlaps its seed site or NFAT in miR-376a. Low case italic letters represent nucleotide replacement for mutation in the core binding motifs or mismatch in the antisense constructs. Note that functional miRNAs are single-stranded RNA molecules.

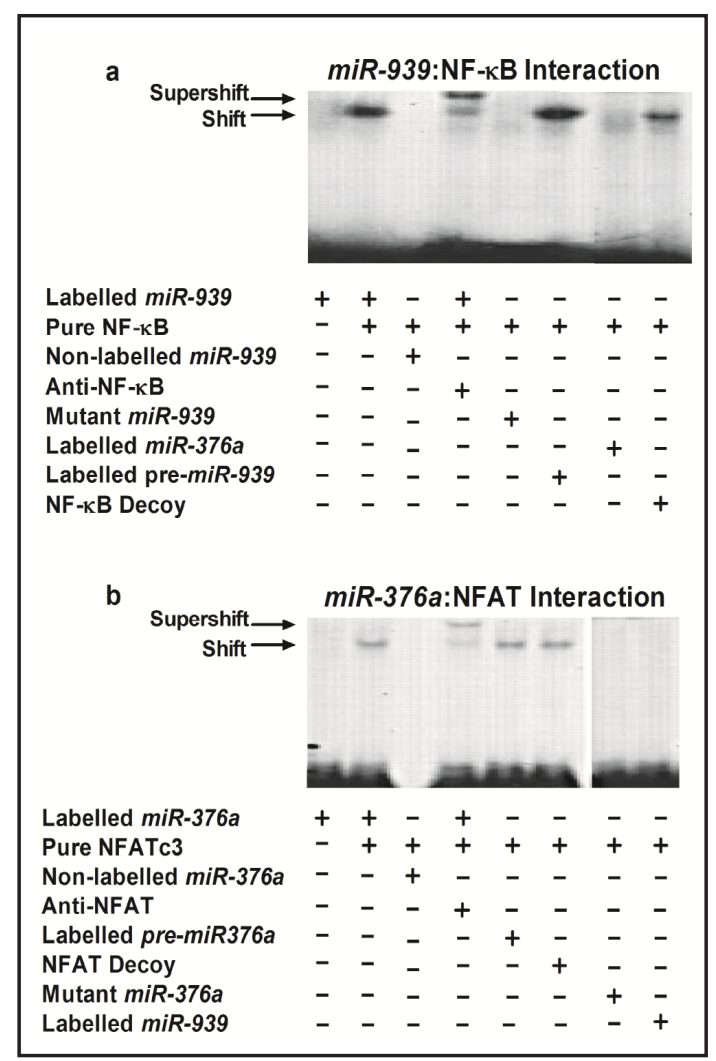

Fig. 2. Verification of the ability of $m i R-939$ and $m i R$ $376 a$, and their precursor miRNAs to bind NF- $\mathrm{BB}$ and NFAT, respectively, using the electrophoresis mobility shift assay (EMSA). (a) EMSA using SH-SY5Y nuclear extract sample showing the physical miR-939:NF$\kappa \mathrm{B}$ interaction. Note the shift and supershift bands

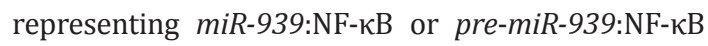
binding, and the lack of interaction between mutant miR-939 and miR-376a and NF- $\kappa$ B protein. (b) EMSA showing the physical miR-376a:NFAT interaction. Note the shift and supershift bands representing $m i R$ 376a:NFAT or pre-miR-376a:NFAT binding, and the lack of interaction between mutant miR-376aand miR939 and NFAT protein.

\section{Results}

Analysis of putative TF cis-elements in miR-376a and miR-939

As the first step to exploit the possibility of miR-939 and miR-376a to act as decoy molecules, we computationally analyzed these two miRNAs for the existence of TF binding sites (cis-acting elements) using the MatInspector V2.2 program (Genomatix). Our analysis revealed that miR-939 bears a 'cis-acting site' for nuclear factor-kappa B p50 subunit (NF$\kappa \mathrm{B} / \mathrm{p} 50)[23,24]$, which is located at its 5 '-end region 2-8 nts exactly overlapping with its 'seed site' (Fig. 1), and miR-376a contains a 'cis-acting site (GGAAA)' for NFATc3 (Fig. 1) [25, 26]. In general, NF- $\kappa B$ is an antiapoptotic factor in neurons which can transactivate survival genes like Bcl-xL $[17,18,27,28]$, whilst NFATc3 is a proapoptotic molecule in neurons that can transactivate Fas ligand (FasL) expression $[29,30]$. 
Physical interaction between miR-376a/miR-939 and TFs

Verification of the ability of $m i R-939$ and $m i R-376 a$ to specifically interact with their corresponding TFs is a key to establish the role of these miRNAs in regulating gene expression at the transcriptional level. To this end, we first carried out EMSA with the purified TF proteins. All miRNAs under test were digoxin-labeled and used as probes for detection. As expected, all miRNAs studied were able to bind with their corresponding TFs. The results are shown in Fig. 2, where the bindings between the TFs and the miRMAs are indicated by appearance of up-shift of the probe bands. Several control experiments were conducted to verify the results. (1) The density of the shifted bands was substantially weakened after the unlabeled miRNAs had been premixed with the labeled with probes. (2) As a positive

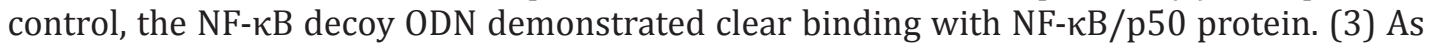
negative controls, miR-939 (Fig. 2a) and miR-376a (Fig. 2b) failed to cause any shifts with AP1 proteins. (4) Neither the mutated miR-939 with the NF- $\mathrm{BB}$ cis-element being disrupted, or the mutated miR-376a with NFAT cis-element being disrupted, nor the scrambled decoy ODN, were able to bind to NF- $\mathrm{kB} / \mathrm{p} 50$ protein.

To further confirm the ability of endogenous miRNAs to interact with endogenous TFs in the physiological context, we immunoprecipitated the TFs using their respective antibodies, with which the interacting miRNAs should be co-precipitated along with their corresponding TFs and be detected by real-time RT-PCR. Our data indeed verified the physical binding of NF- $\kappa \mathrm{B}$ to its cis-element in the promoter region of the bcl-xL gene (Fig. 3a) and NFATc3 to its cis-element in the promoter region of the FasL gene (Fig. 3b). Notably, incubation of cells with miR-939 nearly abrogated the binding of NF- $\mathrm{KB}$ to Bcl-xL promoter, presumably by competing with the binding motif in the promoter region of $\mathrm{Bcl}-\mathrm{xL}$, while incubation

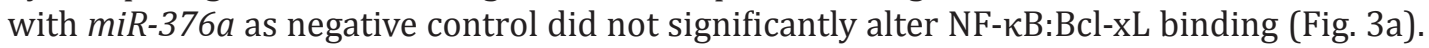
Similarly, miR-376a abolished the interaction between NFAT and FasL promoter, whereas miR-939 failed to affect NFAT:FasL interaction (Fig. 3b). As a negative control, we excluded the cross-binding among the miRNAs and the TFs.

In addition to the above miRNA-promoter competition experiments, we further investigated the direct interaction between NF- $\mathrm{KB}$ and $m i R-939$, and between NFAT and $m i R-376 a$, by crosslinking the immunoprecipitates followed by RT-PCR amplification of pre$m i R-939$ and pre-miR-376a. Our results depicted in Fig. $3 \mathrm{c}$ and $3 \mathrm{~d}$ clearly show the ability of pre-miR-939 to bind NF- $\mathrm{\kappa B}$ and pre-miR-376a to bind NFAT.

\section{Transcriptional regulation of luciferase gene by miR-376a and miR-939}

The physical interactions between the miRNAs and the TFs described above strongly indicate that miRNAs can likely exert transcriptional regulation of gene expression by decoylike actions as decoy:TF binding is the key mechanism for the actions. This is evidenced by our functional assay with luciferase reporter gene expression vectors carrying the perfect cis-element for each of the TFs separately, as the standard test systems.

As illustrated in Fig. 4a, miR-939 at $20 \mathrm{nM}$ significantly inhibited luciferase activities elicited by the luciferase vector carrying the Bcl-xL promoter region spanning the NF- $\mathrm{BB}$ binding motif (NF- $\kappa \mathrm{B} /$ luciferase vector) in transfected HEK293 cells. This inhibitory effect was prevented by co-transfection with miR-939 inhibitor. Moreover, as a negative control, the mutated miR-939, with the NF- $\mathrm{KB}$ binding site disrupted (nucleotides replacement), failed to affect the luciferase activity. These results indicate the specificity of $m i R-939$ actions (Fig. 4a). Furthermore, $m i R-939$ did not affect the luciferase activity with the NF- $\kappa B$ mutant/luciferase vector (Fig. 4a), neither did it cause cross effects on the luciferase activities expressed by the luciferase vector carrying the FasL promoter region spanning the NFAT binding motif (NFAT/luciferase vector; Fig. 4a), indicating the specificity of actions of miR-939 on NF- $\kappa$ B. As a positive control, a decoy ODN targeting NF- $\kappa B$ (NF- $\kappa$ B decoy), caused qualitatively the same repressive effect with the NF- $\kappa B$ /luciferase vector (Fig. 4a). Finally, as anticipated, similar inhibitory effects on NF- $\mathrm{BB} /$ luciferase activity were consistently reproduced with the precursor miR-939 sequence with the loop removed to avoid Dicer processing into mature miR-939 (pre-miR-939; Fig. 4a), and the effect was abolished by miR-939 inhibitor. 
Fig. 3. Verification of the ability of $\mathrm{NF}-\kappa \mathrm{B}$ and NFAT to bind to miR-939 and $m i R-376 a$, and their precursor miRNAs, respectively, in SH-SY5Y human neuroblastoma cells. (a) Evidence for the presence of NF$\kappa \mathrm{B}$ on its cis-acting elements in the promoter region of the Bcl-xL gene, using chromatin immunoprecipitation (ChIP) assay. NFAT and lamin A were used as negative controls. The recovered DNA by anti-NF- $\kappa \mathrm{B} /$ p50 to indicate the relative level of $\mathrm{NF}-\kappa \mathrm{B}$ :Bcl-xL binding was measured by qPCR following ChIP and is expressed as fold changes over antilamin A band. Lane 1: DNA marker; lane 2: the PCR-amplified band using CPSF1 primer pairs and human genomic DNA without immunoprecipitation; lane 3: the PCR-amplified band using CPSF1 primer pairs and human genomic DNA after anti-NF$\kappa \mathrm{B} / \mathrm{p} 50$ immunoprecipitation as a template; lane 4: the PCR-amplified band using CPSF1 primer pairs and human genomic DNA after NFAT antibody immunoprecipitation as a template for negative control; lane 5: the PCR-amplified band using CPSF1 primer pairs and human genomic DNA after lamin-A antibody immunoprecipitation as a template for negative control. ${ }^{* * *} p<0.001$, $\mathrm{n}=3$. (b) Evidence for the presence

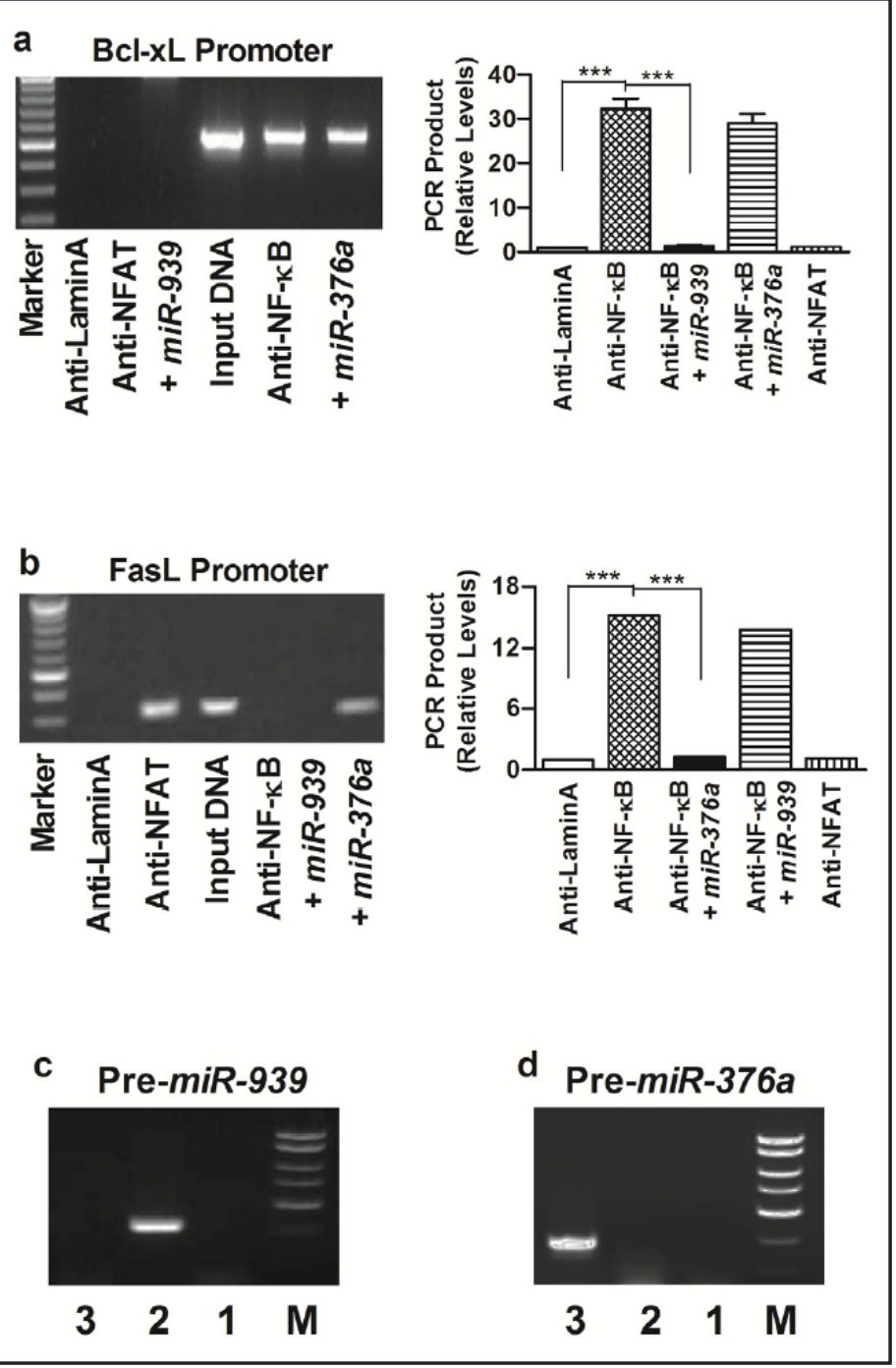

of NFAT on its cis-acting elements in the promoter region of the FasL gene using chromatin immunoprecipitation (ChIP) assay. NF- $\kappa$ B and lamin A were used as negative controls. The recovered DNA by anti-NFATc3 to indicate the relative level of NFAT:miR-376a binding was measured by qPCR following ChIP and is expressed as fold changes over anti-lamin A band. Lane 1: DNA marker; lane 2: the PCR-amplified band using miR-376a primer pairs and human genomic DNA without immunoprecipitation; lane 3: the PCR-amplified band using miR-376a primer pairs and human genomic DNA after anti-NFAT immunoprecipitation as a template; lane 4: the PCR-amplified band using $m i R-376 a$ primer pairs and human genomic DNA after NF- $\mathrm{BB}$ antibody immunoprecipitation as a template for negative control; lane 5: the PCR-amplified band using $m i R-376 a$ primer pairs and human genomic DNA after lamin-A antibody immunoprecipitation as a template for negative control. ${ }^{* *} p<0.001, \mathrm{n}=3$. (c) Evidence for the binding of NF- $\mathrm{BB}$ to pre-miR-939, acquired by PCR following immunoprecipitation with NF- $\mathrm{BB}$ antibody. M: DNA maker; lane 1: negative control without reverse transcriptase; lane 2: pre-miR-939; lane 3: pre-miR-376a. (d) Evidence for the binding of NFAT to pre-miR-376a, acquired by PCR following immunoprecipitation with NFAT antibody. M: DNA maker; lane 1: negative control without reverse transcriptase; lane 2: pre-miR-939; lane 3: pre-miR-376a.

As an additional negative control for cross action, miR-376a did not affect luciferase activity.

Similar effects were observed with $m i R-376 a$, which acted only on the NFAT/luciferase vector, but not on NF- $\mathrm{kB} /$ luciferase vector (Fig. $4 \mathrm{~b}$ ). The mutant miR-376a with the NFAT binding site disrupted but the seed site kept intact lost the ability to inhibit the luciferase 
Fig. 4. Evidence for gene expression regulation at the transcriptional level by $m i R-939$ and $m i R-376 a$ as reported by luciferase reporter activity assay. (a) Effects of miR-939 on luciferase activity generated by the luciferase vector carrying Bcl-xL promoter spanning the putative NF- $\mathrm{KB}$ binding motif. Control: transfection of luciferase vector alone; miR-939: co-transfection of luciferase vector with miR-939; miR-939-I: miR-939 inhibitor; MT miR-939: mutant miR-939; MT NF-kB-V: the luciferase vector carrying mutant NF- $\kappa B$ binding site; NFAT-V: the luciferase vector carrying FasL promoter spanning the putative

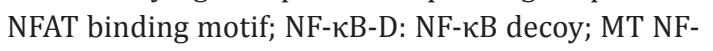

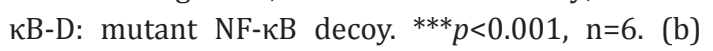
Effects of $m i R-376 a$ on luciferase activity generated by the luciferase vector carrying FasL promoter spanning the putative NFAT binding motif. miR376a-I: miR-376a inhibitor; MT miR-376a: mutant miR-376a; MT NFAT-V: the luciferase vector carrying mutant NFAT binding site; NF-KB-V: the luciferase vector carrying $\mathrm{Bcl}-\mathrm{xL}$ promoter spanning the putative NF- $\mathrm{KB}$ binding motif; NFAT-D: NFAT decoy; MT NFAT-D: mutant NFAT decoy. ${ }^{* * *} p<0.001, \mathrm{n}=5$. (c) Effects of NF- $\kappa B$ ORN and NFAT ORN on luciferase gene activities. NF-KB ORN is the NF-kB decoy (NF$\mathrm{kB}-\mathrm{D}$ ) in the form of RNA and NFAT-ORN is the NFAT decoy (NFAT-D) in the form of RNA. ${ }^{* * *} p<0.001, \mathrm{n}=5$.
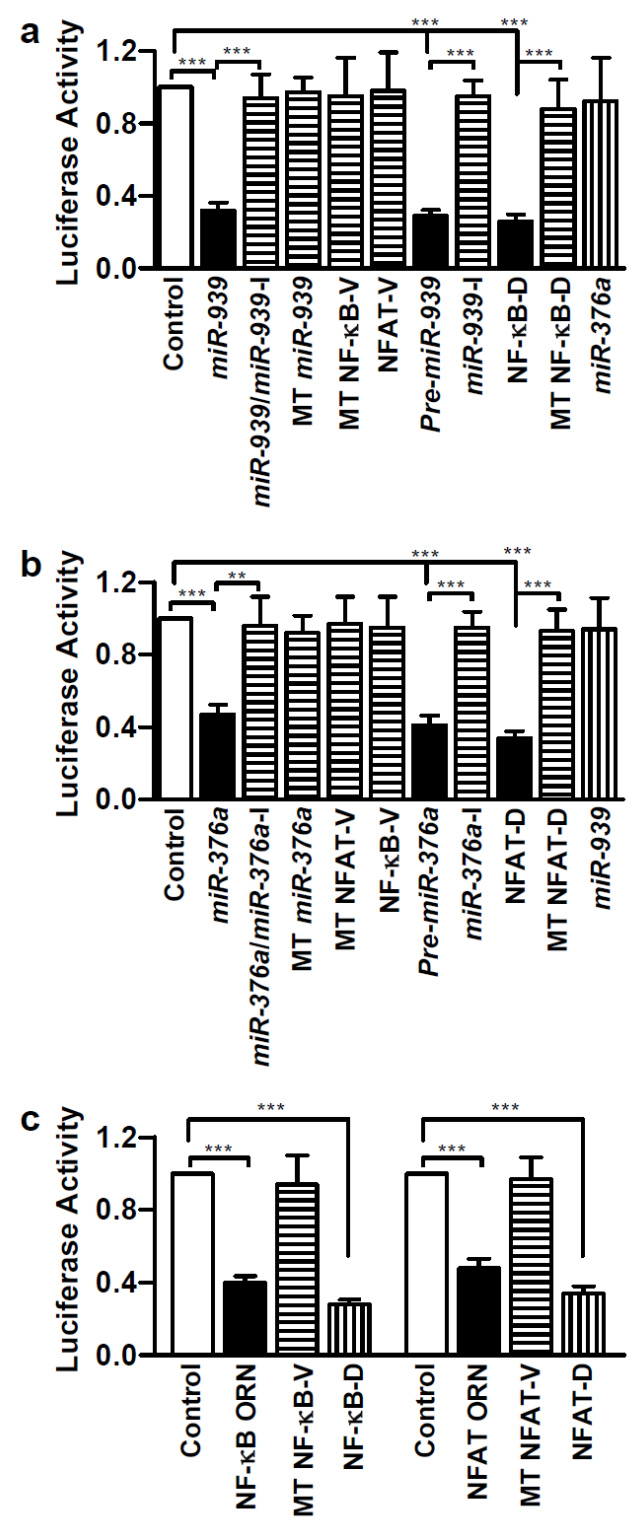

activity. As anticipated, similar effects were consistently reproduced with the precursor $m i R$ $376 a$ with the loop removed to avoid Dicer processing into mature miR-376a (pre-miR-376a; Fig. 4b).

The efficacy of pre-miRNAs in depressing luciferase activity argued against the possibility of post-transcriptional repression of expression of the luciferase gene in our study. Using the mRNA target prediction, we did not find any 'seed sites' for miR-939 or miR$376 a$ in the 3'UTR and any other regions in the luciferase vector.

To further verify that double-stranded RNA in general can functionally interact with TFs, we converted the NF- $K B$ and NFAT decoy ODNs into equivalent RNA sequences (decoy ORNs which are comprised of two complementary RNA oligonucleotides annealed together) and demonstrated the ability of these decoy ORNs to suppress luciferase activities elicited by the luciferase vectors containing the corresponding TF sites (Fig. 4c).

We then sought to investigate the role of endogenous miR-939 and miR-376a-1 in regulating luciferase activities by "loss-of-function" approach using the anti-miRNA 2'-O-methyl oligonucleotides inhibitors. If the endogenous miRNAs can produce 


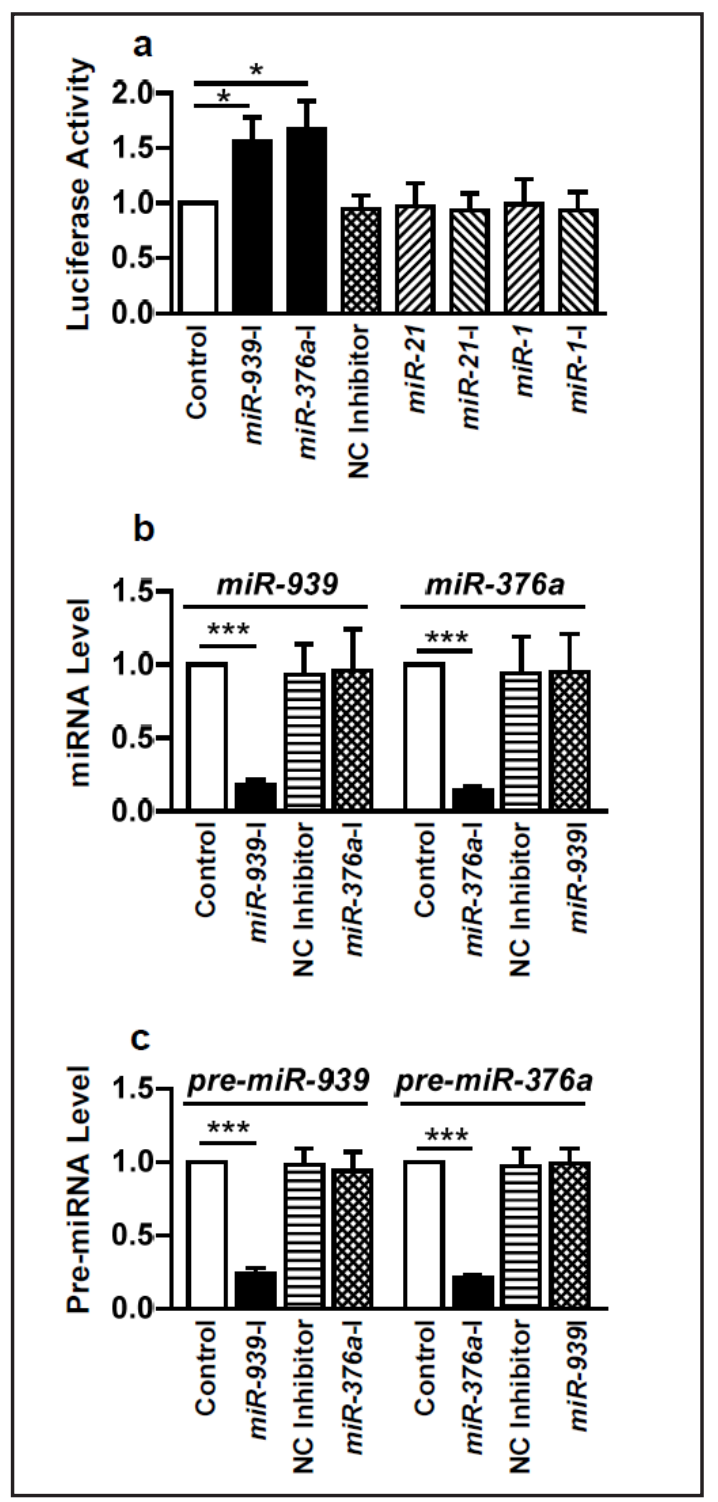

Fig. 5. Verification of the role of endogenous miRNAs/pre-miRNAs in transcriptional regulation of gene expression. (a) Effects of miR-939 and miR$376 a$ inhibitors (miR-939-I and miR-376a-I, respectively) on luciferase gene activities (NFAT luciferase vector) as an indication of tonic decoy function imposed by endogenous miR-939 and miR-376a. NC Inhibitor: scrambled antisense inhibitor. Note that miR-21 and miR-1as negative controls failed to affect luciferase activity. ${ }^{*} p<0.05, \mathrm{n}=5$. (b) Verification of the efficacy of miRNA inhibitors to knockdown their respective miRNAs, using quantitative real-time RTPCR methods. ${ }^{* * *} p<0.001, \mathrm{n}=5$. (c) Verification of the efficacy of miRNA inhibitors to knockdown their respective pre-miRNAs. ${ }^{* * *} p<0.001, \mathrm{n}=5$.

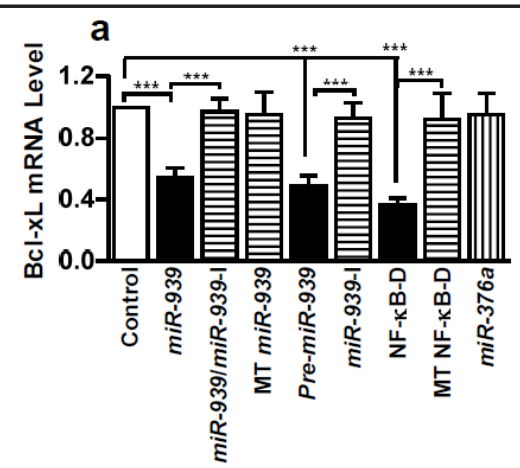

b
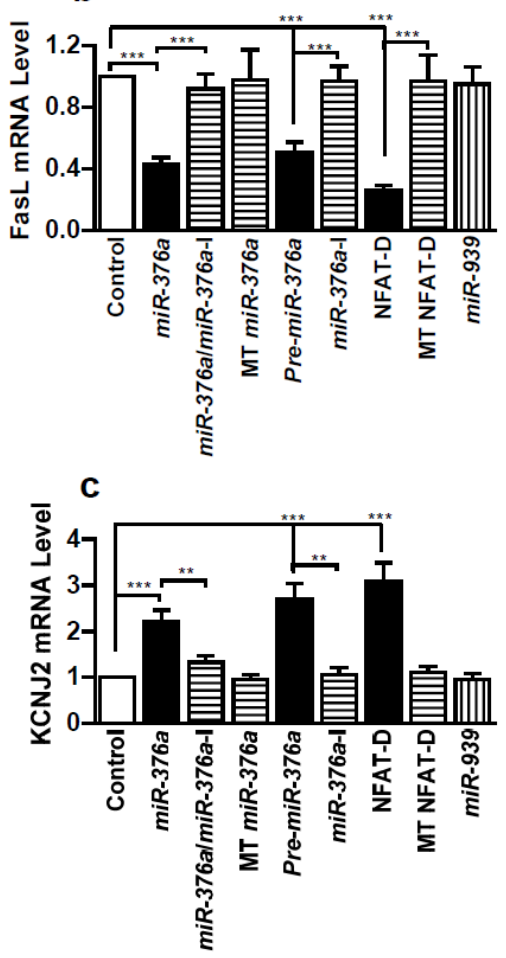

Fig. 6. Transcriptional regulation of $\mathrm{Bcl}-\mathrm{xL}$, FasL and miR-26 genes by miR-939 and miR-376a. (a) Transcriptional repression of Bcl-xL expression by $m i R-939$, determined by quantitative real-time RT-PCR in SH-SY5Y human neuroblastoma cells. ${ }^{* *} p<0.01$ and ${ }^{* * *} p<0.001 ; \mathrm{n}=6$. (b) Transcriptional repression of FasL expression by miR-376a in SHSY5Y human neuroblastoma cells. ${ }^{* *} p<0.01$ and ${ }^{* * *} p<0.001 ; \mathrm{n}=6$. (c) Transcriptional stimulation of miR-26 expression by miR-376a in $\mathrm{H} 9 \mathrm{c} 2$ rat ventricular cells. ${ }^{* *} p<0.01$ and ${ }^{* * *} p<0.001 ; \mathrm{n}=6$. miR-376a-I: miR-376a inhibitor; MT miR-376a: mutant miR-376a; NFAT-D: NFAT decoy; MT NFAT-D: mutant NFAT de-

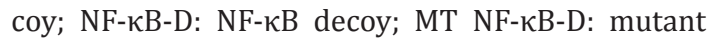
NF- $\kappa$ B decoy.

transcriptional regulation of gene expression, then application of miRNA inhibitors alone should be able to alter luciferase activity. Our experiments indeed verified this notion: the 
synthetic inhibitors to $m i R-939$ and $m i R-376 a$ remarkably enhanced the luciferase activities induced by the corresponding luciferase vectors in SH-SY5Y cells (Fig. 5a); for instance, miR$376 a$ inhibitor increased the luciferase activity (by 70\%) induced by the NFAT luciferase vector. Neither the scrambled inhibitor (NC Inhibitor) nor the inhibitors to $m i R-1$ and $m i R$ 21 as negative controls produced any appreciable effects on luciferase activities (Fig. 5a). The efficacy of the inhibitors to cause sequestration or induce degradation of their target miRNAs (Fig. 5b) and precursor miRNAs (Fig. 5c) was verified using qRT-PCR.

Transcriptional regulation of endogenous genes by miR-376a and miR-939

It has been demonstrated that decoy ODNs can block the function of TFs without penetrating into the nucleus as proteins including TFs are all synthesized outside the nucleus and sequestration of TFs by decoy ODNs in the cytoplasm expectedly prevents these TFs from being translocated into nucleus to take actions [7]. By the same mechanism, mature miRNAs that are normally generated in the cytoplasm should also be able to block the actions of TFs by the same mechanism. While our results presented in earlier sections clearly indicate the physical miRNA:TF interactions and the regulation of gene expression consequent to the interactions, it has not been shown whether the transcriptional regulation induced by miRNAs operates in the physiological context. To clarify this issue, we carried out qRT-PCR measurements of selected genes that have been known to be transcriptionally regulated by NF- $\kappa B$ and NFATc3, based on published studies. It has been shown that application of NF- $\kappa B$ activator to SH-SY5Y human neuroblastoma cells significantly increased the level of Bcl-xL mRNA that encodes the anti-apoptotic protein BCL-xL $[17,18]$. In the present study, miR-939 considerably decreased Bcl-xL transcript concentration, an effect abrogated by co-transfection with its inhibitor (Fig. 6a). Similar effects were consistently observed with pre-miR-939, which was also abolished by miR-939 inhibitor. The mutant construct failed to produce any appreciable effects on Bcl-xL transcript, neither did miR-376a.

On the other hand, miR-376 reduced the transcript level of FasL (Fig. 6b) encoded by the FASLG gene in the same manner as miR-939 did on Bcl-xL. Furthermore, it has recently been shown that NFATc3 transcriptionally represses expression of the KCNJ2 gene that encodes a $\mathrm{K}^{+}$channel subunit Kir2.1 [19]. There is a possibility then that miR-376a is able to regulate KCNJ2 expression through decoying NFAT. Our results indeed demonstrated that either miR-376a or pre-miR-376a caused massive upregulation of KCNJ2 level in cultured $\mathrm{H} 9 \mathrm{c} 2$ ventricular cells, and the effects were mitigated or eliminated by miR-376a inhibitor (Fig. 6c).

\section{Cellular function of miR-376a and miR-939 as decoy molecules}

We then sought to exploit the cellular function as the outcomes of the transcriptional regulation of gene expression by miRNAs. One common feature of NF- $\kappa B$ and NFAT is that these TFs have all been known to play crucial roles in cell death (apoptosis) and cell proliferation. $\mathrm{NF}-\kappa \mathrm{B}$ is primarily a survival factor with strong anti-apoptotic and proliferation-stimulating effects in neurons $[27,28,31,32]$, whilst NFAT mainly cause apoptotic cell death of neurons $[29,30,33]$. We therefore set out to test whether miR-939/pre-miR-939 and miR-376a/premiR-376a regulate apoptosis in human neuroblastoma cell line SH-SY5Y cells.

The anticancer agent doxorubicin has been shown to induce apoptosis accompanied by activation of NF- $\mathrm{BB}$ in neuroblastoma SH-SY5Y cells [34-36], which likely produces protective role against doxorubicin-triggered cell death. We observed that miR-939/ pre-miR-939 promoted apoptosis induced by doxorubicin, as indicated by the decreased percentage of survival cells measured by MTT (Fig. 7a) and the increased optical density (OD) values measured by ELISA (Fig. 7b) and TUNEL (Fig. 7c) for DNA fragmentation. NF$\kappa \mathrm{B}$ decoy evoked similar pro-apoptotic effects as $m i R$-939. In contrast, $m i R-376 a / p r e-m i R-$ $376 a$, as well as NFAT decoy, protected against apoptosis (Fig. 7d, e, f), which is consistent with published studies showing that NFAT is a mediator of doxorubicin-induced apoptosis in glioma cells [37] and T-lymphocytes [38]. The effects of these miRNAs/pre-miRNAs on SH-SY5Y apoptosis were all abolished when co-transfected their respective inhibitors. 


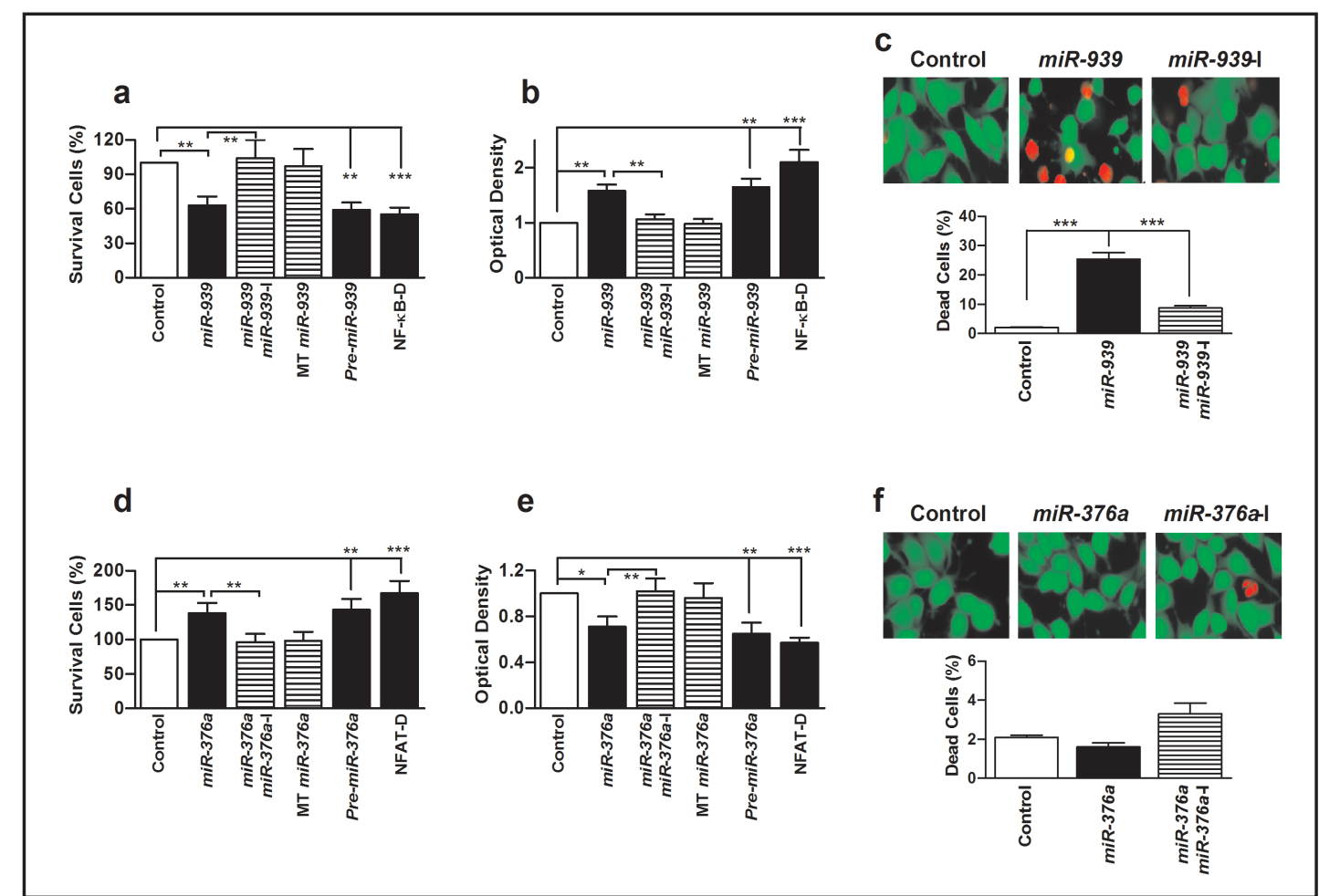

Fig. 7. Contrasting effects of miR-939 and miR-376a on cell death of SH-SY5Y human neuroblastoma cells. (a) Reduction of cell survival rate by $m i R-939$, as determined by MTT assay. ${ }^{* *} p<0.01$ and ${ }^{* * *} p<0.001 ; \mathrm{n}=6$. (b) Increased in DNA fragmentation indicating the proapoptotic effect of $m i R-939$, as determined by ELISA. ${ }^{* *} p<0.01$ and ${ }^{* * *} p<0.001 ; \mathrm{n}=6$. (c) Increased in DNA fragmentation detected by TUNEL staining indicating the proapoptotic effect of miR-939 (stained in red). Upper panels: examples of TUNEL staining images; lower panels: percentage of TUNEL positive cells (dead cells). ${ }^{* * *} p<0.001 ; n=3$. (d) Increase of cell survival rate by $m i R-376 a$, as determined by MTT assay. ${ }^{* *} p<0.01$ and ${ }^{* * *} p<0.001 ; \mathrm{n}=6$. (e) Decreased in DNA fragmentation indicating the antiapoptotic effect of $m i R-376 a$, as determined by ELISA. ${ }^{*} p<0.05,{ }^{* *} p<0.01$, and ${ }^{* * *} p<0.001 ; \mathrm{n}=6$. (f) DNA fragmentation detected by TUNEL staining in cells treated with $m i R-376 a$ or miR$376 a+$ miR-376a-I. Upper panels: examples of TUNEL staining images; lower panels: percentage of TUNEL positive cells (dead cells). $n=3$.

Additionally, the mutant negative controls for the miR-376a and miR-939 did not produced any appreciable effects on cell death, whereas their positive control decoy ODNs (NF- $\kappa B$ and NFAT decoys) gave rise to similar results as the miRNAs/pre-miRNAs.

\section{Discussion}

Here we reported a non-canonical mechanism of miRNAs miR-939 and miR-376a several acting as endogenous decoy molecules to sequestrate transcription factors NF- $\kappa B$ and NFAT to produce transcriptional regulation of gene expression leading to altered cellular functions associated with these TFs, in addition to their canonical actions through the seed-site mechanism. A number of lines of evidence are provided in support of this novel mechanism. First, miR-939 and miR-376a can physically interact with NF- $\kappa \mathrm{B}$ and NFAT, respectively, which is conferred by the cis-elements carried within the sequences of mature miRNAs. Moreover, miR-939 and miR-376a can produce transcriptional regulation of luciferase reporter gene expression and luciferase activities with the luciferase vector carrying the NF$\kappa \mathrm{B}$ and NFAT cis-acting elements in its promoter region. Moreover, miR-939 and miR-376a 
produced transcriptional regulation of endogenous genes Bcl-xL and FasL/miR-26 that are the transcriptional targets for NF-kB and NFAT, respectively, but are not post-transcriptional targets for these two miRNAs. In particular, miR-939 downregulated BcL-xL transcript, and miR-376a downregulated FasL mRNA but upregulated miR-26 consistent with sequestration of NFAT. Finally, interference of these miRNAs with NF- $\kappa B$ and NFAT demonstrated clear phenotypes at the cellular level as manifested by the regulation of neuroblastoma cell death by $m i R-939$ and $m i R-376 a$. Strikingly, precursors miR-939 and miR-376a elicited qualitative the same effects as their respective mature counterparts, whilst mutations made to the cis-acting elements within the mature sequence of miR-376a eliminated the actions of the wild-type miRNA and the antisense inhibitors of miR-939 and miR-376a effectively blocked the actions of these two miRNAs. Our study therefore identified a novel non-canonical mechanism of actions of miRNAs and suggests that when considering the cellular function of miRNAs the decoy-like mechanism for transcriptional regulation (activation or repression), in addition to the commonly recognized seed-site mechanism for post-transcriptional repression, should be taken into account.

Ever since their discovery, miRNAs have been believed to exclusively produce posttranscriptional regulation of gene expression $[39,40]$. The data presented here however breaks this dogma; miRNAs can regulate gene expression at the transcriptional level. In other words, miRNAs actually function through dual mechanisms in a cell: transcriptional and post-transcriptional regulations. Dual functions of miRNAs are conferred by the dual sites contained in the sequence of a miRNA: the 'seed site' for target mRNA binding to elicit post-transcriptional regulation and the 'cis-acting site' for target TF binding to produce transcriptional regulation. While the 'seed site' is fixed at the 5'-end 2-8 nucleotides, the 'cis-acting site' may exist in any regions along the sequence of a miRNA. miRNAs are known for their ability to post-transcriptionally silence gene expression. This unique function is fulfilled by binding the target mRNAs through a partial complementary mechanism to trigger the RISC machinery and so as to hinder the protein translation process and/or degrade the targeted mRNAs. The transcriptional regulation of gene expression by miRNAs reported in this study has not been previously noticed. One of the explanations for that may be that the genes regulated by a given miRNA through the two distinct pathways (transcriptional and post-transcriptional) are different. Another possible explanation may be that the transcriptional regulation by miRNAs is indirectly via acting on TFs, deferring from direct actions on genes. The presence of this alternative mode of actions at the transcriptional level is confirmed by the four converging lines of experimental evidence, including the physical bind between miRNAs and TFs as revealed by our EMSA experiments, altered gene expression by miRNAs determined by our luciferase reporter activity assay, real-time RTPCR quantification of mRNA levels, and functional evaluation of cell death. It is therefore speculated that transcription of a gene is under the control of both TFs and miRNAs, or more specifically of the balance between TFs and miRNAs. Nonetheless, whether our results obtained from miR-939 and miR-376a can be extrapolated to other miRNAs requires broader surveys of more miRNAs.

This study established that the transcriptional regulation produced by miRNAs is ascribed to their binding to transcriptional factors through the decoy action in addition to their well-recognized ability to bind target mRNAs to repress translation via the RISC mechanism. This finding clearly indicates the presence of endogenous decoy molecules in mammalian cells; differing from the known exogenous decoy oligodeoxynucleotides (decoy ODNs), miRNAs are endogenous decoy oligoribonucleotides (decoy ORNs). MiRNAs as the endogenous decoy molecules are supported by three lines of evidence. First, our EMSA experiments revealed the physical associations between TFs and mature miRNAs/ pre-miRNAs that contain the putative binding motifs of these TFs. In other words, miRNAs are able to bind and absorb the targeted TFs. Second, the miRNA:TF interactions bring about functional outcomes. A miRNA can alter the promoter activities if the miRNA and the promoter contain the same cis-element for a TF. Quenching of TFs by miRNAs renders a loss of the regulatory functions in gene transcription. Third, mutations in the TF binding sites 
contained in the miRNA sequences without destructing the seed sites for RISC interactions. And finally, perhaps most importantly, the antisenses against either the mature or the precursor miRNAs can efficiently reverse the transcriptional regulatory effects of these miRNAs. Interesting to note is the report by Davis et al that specific transcription factors (SMAD) can bind miRNA precursors (pre-miR-21) [41].

Another conceptual advance brought by this study to our understanding of the function of miRNAs is that while by the RISC mechanism miRNAs exclusively repress translation process, by the decoy mechanism they can either downregulate/repress/silence or upregulate/enhance/activate gene expression, depending upon the actions of their targeted TFs. This finding suggests that the existing dogma that miRNAs can only silence expression of genes no longer holds; while a given miRNA may repress translation of its target genes by the RISC mechanisms it can also enhance transcription of other genes by the decoy mechanism.

Also notable is our finding that pre-miRNAs exert regulatory effects on gene expression at the transcriptional level through the decoy mechanism in spite of their inability to produce post-transcriptional repression via the RISC pathway. This prompts to revise the general believe that pre-miRNAs are of no cellular functions being merely the intermediates of miRNA biogenesis [42]. It is noteworthy that the ability offered by precursor miRNAs to target TFs to produce transcriptional regulation of related genes may or may not be preserved in their mature counterparts depending upon whether the binding sites for the TFs are contained within the shorter mature sequences. If a particular TF binding element is carried by a mature miRNA, then one expects to observe the decoy actions from both mature and precursor forms. This is the case for the present study; the cis-elements for NF- $\kappa \mathrm{B}$ and NFAT are located within the regions of mature miR-939 and $m i R-376 a$, respectively. In the case that TF binding site is located outside a mature sequence and within the precursor sequence, the pre-miRNA is likely functional via decoy-like actions. It is therefore no doubt that miRNAs in their precursor form with longer sequences are always capable of decoying more TF species than in their mature form at shorter segments.

NF- $\kappa B$ is generally composed of two subunits, p50 and p65, that associate with a third protein, $\mathrm{I} \kappa \mathrm{B}$, in many cell types [43]. p65 primarily binds to motif with a core containing "GGAA", whereas p50 binds to motif with a core of "GGGRN" where R indicates A or G, and $\mathrm{N}$ indicates any nucleotide [23]. In our case, miR-939 contains "GGGRN"; thus it should preferentially bind to p50. However, there is a possibility that miR-939 can also bind to p65, which merits future studies to verify. Additionally, NF- $\mathrm{kB}$ has been linked to a wide variety of signaling mediators such as JNK, AP-1 and MAPK, aside from Bcl-xL $[44,45]$. It would be important to clarify in the future whether these other factors are also regulated by miR-939 through decoy-like action on NF- $\mathrm{BB}$.

One of the characteristics of miRNAs is that each individual miRNA possess the potential to post-transcriptionally repress multiple target genes (ranging from a few decades to a few hundreds of mRNAs). Similarly, each individual TF also regulates multiple genes. This latter property determines that each individual miRNA has the potential to transcriptionally regulate multiple genes. Probably more important is the perspective that a given miRNA regulate two distinct populations of genes: one depending on its 'seed site' target mRNAs and the other on its TF 'cis-acting site' target genes. For example, miR-376a has putative target genes when operating with the RISC mechanism, but has a different set of target genes when operating with the decoy mechanism. One interesting issue raised from our findings is that post-transcriptionally, miRNAs can regulate only protein-coding genes, but transcriptionally, they can also regulate miRNA-coding genes. For instance, we showed here that miR-376a upregulated miR-26 expression. This mechanism of miRNA-regulation-of-miRNA is another novel function of miRNAs.

While the predominant anti-apoptotic activity of NF- $\kappa \mathrm{B}$ contributes to its oncogenic capacity, the pro-apoptotic favor NFAT as a potent tumor suppressor at least in neuroblastomas, may be ascribed to the regulation of expression of hundreds of proteincoding genes. Many variants of cancer are characterized by elevated constitutive activity of $\mathrm{NF}-\kappa \mathrm{B}$, which can act as a survival factor for malignant cells and an important obstacle in 
many cancer therapies. Moreover, NF- $\mathrm{BB}$ is an essential factor in acute as well as chronic inflammation, a pathological state which is either cause or co-factor in a great variety of diseases [31, 32]. Our results showed that miR-939/pre-miR-939 and miR-376a/pre-miR$376 a$ can directly target NF- $\kappa B$ and NFAT, respectively, leading to significant outcomes on cell death. The findings indicate that these miRNAs not only are the vital components of NF- $\mathrm{BB}$ and NFAT networks but can also be considered as miRNA oncomers or tumor suppressors by their decoy property $[46,47]$, providing a novel, alternative approach for cancer therapy through interfering these miRNAs $[48,49]$. Thus, our data revealed novel cellular functions of $m i R-939$ and $m i R-376 a$, in addition to their role in regulating inducible nitric oxide synthase expression in hepatocytes [15] and invasiveness of glioblastoma cells [16], respectively.

The present study was not able to elucidate the relationships between the transcriptional regulation and post-transcriptional repression of gene expression by miRNAs; how these two different mechanisms operate to coordinate the delicate yet dynamic balances of regulation under various conditions. More studies are definitely required to establish the relationships between miRNAs and TFs by including more miRNAs and TFs for experimental examination, and to delineate the pathophysiological significance of these relationships by implementing experiments in the in vivo settings. We also failed in this study to define whether other types of RNAs in addition to miRNAs can also act as decoy molecules to produce transcriptional regulation of gene expression and what exactly the structural features are required for a miRNA to be able to interact with TFs though our results suggest that double strand structure and $\mathrm{TF}$ binding sequence are two important conditions.

\section{Conclusions}

In summary, we have identified several novel properties of miRNAs, which has the potential to revise our current view of these unique molecules. The gene expression regulation by miRNAs as endogenous decoy molecules has important implications in cellular functions. Our study revealed a novel, non-canonical mechanism of miRNA function in transcriptionally regulating, either activation or repression depending on the TF activities, protein-coding genes and miRNA-coding genes as well by the decoy-like actions, in addition to the canonical seed-site mechanism for post-transcriptional repression.

\section{Disclosure Statement}

The authors declare no competing financial interests.

\section{References}

1 Roth M: Transcription factors: Are they a real target for future therapeutic strategies? Pharmacologyonline 2005;1:45-66.

2 Bielinska A, Shivdasani RA, Zhang LQ, Nabel GJ: Regulation of gene expression with double-stranded phosphorothioate oligonucleotides. Science 1990;250:997-1000.

-3 Morishita R, Sugimoto T, Aoki M, Kida I, Tomita N, Moriguchi A, Maeda K, Sawa Y, Kaneda Y, Higaki J, Ogihara T: In vivo transfection of cis element "decoy" against nuclear factor-kappaB binding site prevents myocardial infarction. Nat Med 1997;13:894-899.

4 Mann MJ, Dzau VJ: Therapeutic applications of transcription factor decoy oligonucleotides. J Clin Invest 2000;106:1071-1075.

5 Gambari R: New trends in the development of transcription factor decoy (TFD) pharmacotherapy. Curr Drug Targets 2004;5:419-430. 
6 Fichou Y, Ferec C: The potential of oligonucleotides for therapeutic applications. Trends Biotechnol 2006;24:563-570.

7 Morishita R, Higaki J, Tomita N, Ogihara T: Application of transcription factor "decoy" strategy as means of gene therapy and study of gene expression in cardiovascular disease. Circ Res 1998;82:1023-1028.

8 Tomita N, Morishita R, Tomita T, Ogihara T: Potential therapeutic applications of decoy oligonucleotides. Curr Opin Mol Ther 2002;4:166-170.

-9 Lewis BP, Burge CB, Bartel DP: Conserved seed pairing, often flanked by adenosines, indicates that thousands of human genes are microRNA targets. Cell 2005;120:15-20.

10 Brennecke J, Stark A, Russell RB, Cohen SM: Principles of microRNA-target recognition. PLoS Biol 2005;3:404-418.

11 Vasudevan S, Tong Y, Steitz JA: Switching from repression to activation: microRNAs can up-regulate translation. Science 2007;318:1931-1934.

12 Yang B, Lu Y, Wang Z: Control of cardiac excitability by microRNAs. Cardiovasc Res 2008;79:571-580.

13 Yang B, Lin H, Xiao J, Lu Y, Luo X, Li B, Zhang Y, Xu C, Bai Y, Wang H, Chen G, Wang Z: The muscle-specific microRNA miR-1 regulates cardiac arrhythmogenic potential by targeting GJA1 and KCNJ2. Nat Med 2007;13:486-491.

14 Miranda KC, Huynh T, Tay Y, Ang YS, Tam WL, Thomson AM, Lim B, Rigoutsos I: A pattern-based method for the identification of MicroRNA binding sites and their corresponding heteroduplexes. Cell 2006;126:12031217.

15 Guo Z, Shao L, Zheng L, Du Q Li P, John B, Geller DA: miRNA-939 regulates human inducible nitric oxide synthase posttranscriptional gene expression in human hepatocytes. Proc Natl Acad Sci U S A 2012;109:5826-5831.

16 Choudhury Y, Tay FC, Lam DH, Sandanaraj E, Tang C, Ang BT, Wang S: Attenuated adenosine-to-inosine editing of microRNA-376a* promotes invasiveness of glioblastoma cells. J Clin Invest 2012;122:4059-4076.

17 Khoshnan A, Tindell C, Laux I, Bae D, Bennett B, Nel AE: The NF-kappa B cascade is important in Bcl-xL expression and for the anti-apoptotic effects of the CD28 receptor in primary human CD4+ lymphocytes. J Immunol 2000;165:1743-1754.

18 Takase O, Minto AW, Puri TS, Cunningham PN, Jacob A, Hayashi M, Quigg RJ. Inhibition of NF-kappaBdependent Bcl-xL expression by cluster in promotes albumin-induced tubular cell apoptosis. Kidney Int 2008;73:567-577.

19 Luo X, Pan Z, Shan H, Xiao J, Sun X, Wang N, Lin H, Xiao L, Maguy A, Qi XY, Li Y, Gao X, Dong D, Zhang Y, Bai Y, Ai J, Sun L, Lu H, Luo XY, Wang Z, Lu Y, Yang B, Nattel S: MicroRNA-26 governs profibrillatory inwardrectifier potassium current changes in atrial fibrillation. J Clin Invest 2013;123:1939-1951.

20 Gao H, Xiao J, Yang B, Sun Q Lin H, Bai Y, Yang L, Wang H, Wang Z: A single decoy oligodeoxynucleotides targeting multiple oncoproteins produces strong anti-cancer effects. Mol Pharmacol 2006;70:1621-1629.

-21 Xiao S, Matsui K, Fine A, Zhu B, Marshak-Rothstein A, Widom RL, Ju ST: FasL promoter activation by IL-2 through SP1 and NFAT but not Egr-2 and Egr-3. Eur J Immunol 1999;29:3456-3465.

22 Xiao J, Lin H, Luo X, Luo X, Wang Z: miR-605 joins p53 network to form a p53:miR-605:Mdm2 positive feedback loop in response to stress. EMBO J 2011;30:524-532.

-23 Wong D, Teixeira A, Oikonomopoulos S, Humburg P, Lone IN, Saliba D, Siggers T, Bulyk M, Angelov D, Dimitrov S, Udalova IA, Ragoussis J: Extensive characterization of NF- $\kappa$ B binding uncovers non-canonical motifs and advances the interpretation of genetic functional traits. Genome Biol 2011;12:R70.

24 Wang Y, Dang J, Wang H, Allgayer H, Murrell GA, Boyd D: Identification of a novel nuclear factor-kappaB sequence involved in expression of urokinase-type plasminogen activator receptor. Eur J Biochem 2000;267:3248-3254.

25 Northrop JP, Ho SN, Chen L, Thomas DJ, Timmerman LA, Nolan GP, Admon A, Crabtree GR: NF-AT components define a family of transcription factors targeted in T-cell activation. Nature 1994;369:497-502.

-26 Badran BM, Wolinsky SM, Burny A, Willard-Gallo KE. Identification of three NFAT binding motifs in the 5 '-upstream region of the human CD3gamma gene that differentially bind NFATc1, NFATc2, and NF-kappa B p50. J Biol Chem 2002;277:47136-47148.

27 Sompol P, Xu Y, Ittarat W, Daosukho C, St Clair D: NF-kappaB-associated MnSOD induction protects against beta-amyloid-induced neuronal apoptosis. J Mol Neurosci 2006;29:279-288. 
28 Valerio A, Boroni F, Benarese M, Sarnico I, Ghisi V, Bresciani LG, Ferrario M, Borsani G, Spano P, Pizzi M: NF-kappaB pathway: a target for preventing beta-amyloid (Abeta)-induced neuronal damage and Abeta42 production. Eur J Neurosci 2006;23:1711-1720.

29 Gómez-Sintes R, Lucas JJ: NFAT/Fas signaling mediates the neuronal apoptosis and motor side effects of GSK-3 inhibition in a mouse model of lithium therapy. J Clin Invest 2010;120:2432-2445.

30 Jayanthi S, Deng X, Ladenheim B, McCoy MT, Cluster A, Cai NS, Cadet JL: Calcineurin/NFAT-induced upregulation of the Fas ligand/Fas death pathway is involved in methamphetamine-induced neuronal apoptosis. Proc Natl Acad Sci U S A 2005;102:868-873.

-31 Fan Y, Dutta J, Gupta N, Fan G, Gelinas C: Regulation of programmed cell death by NF-kappaB and its role in tumorigenesis and therapy. Adv Exp Med Biol 2008;615:223-250.

-32 Egan LJ, Toruner M: NF-kappaB signaling: pros and cons of altering NF-kappaB as a therapeutic approach. Ann N Y Acad Sci 2006;1072:114-122.

-33 Luoma JI, Zirpel L: Deafferentation-induced activation of NFAT (nuclear factor of activated T-cells) in cochlear nucleus neurons during a developmental critical period: a role for NFATc4-dependent apoptosis in the CNS. J Neurosci 2008;28:3159-3169.

34 Wu J, Harris NL, Inge TH: Nuclear factor-kappa B and apoptosis inducing factor activation by doxorubicin analog WP744 in SH-SY5Yneuroblastoma cells. J Surg Res 2004;122:231-239.

-35 Lin X, Li Q, Wang YJ, Ju YW, Chi ZQ, Wang MW, Liu JG: Morphine inhibits doxorubicin-induced reactive oxygen species generation and nuclear factor kappaB transcriptional activation in neuroblastoma SH-SY5Y cells. Biochem J 2007;406:215-221.

-36 Ammann JU, Haag C, Kasperczyk H, Debatin KM, Fulda S: Sensitization of neuroblastoma cells for TRAILinduced apoptosis by NF-kappaB inhibition. Int J Cancer 2009;124:1301-1311.

- 37 Gopinath S, Vanamala SK, Gujrati M, Klopfenstein JD, Dinh DH, Rao JS: Doxorubicin-mediated apoptosis in glioma cells requires NFAT3. Cell Mol Life Sci 2009;66:3967-3978.

38 Kalivendi SV, Konorev EA, Cunningham S, Vanamala SK, Kaji EH, Joseph J, Kalyanaraman B: Doxorubicin activates nuclear factor of activated T-lymphocytes and Fas ligand transcription: role of mitochondrial reactive oxygen species and calcium. Biochem J 2005;389:527-539.

39 Guarnieri DJ, DiLeone RJ: MicroRNAs: a new class of gene regulators. Ann Med 2008;40:197-208.

40 Liu J: Control of protein synthesis and mRNA degradation by microRNAs. Curr Opin Cell Biol 2008;20:214221.

41 Davis BN, Hilyard AC, Lagna G, Hata A: SMAD proteins control DROSHA-mediated microRNA maturation. Nature 2008;454:56-61.

42 Liu X, Fortin K, Mourelatos Z: MicroRNAs: biogenesis and molecular functions. Brain Pathol 2008;18:113121.

43 Baeuerle PA, Baltimore D: A 65-kappaD subunit of active NF-kappaB is required for inhibition of NFkappaB by I kappaB. Genes Dev 1989;3:1689-1698.

44 Sarkar FH, Li Y, Wang Z, Kong D: NF-kappaB signaling pathway and its therapeutic implications in human diseases. Int Rev Immunol. 2008;27:293-319.

-45 Mankan AK, Lawless MW, Gray SG, Kelleher D, McManus R: NF-kappaB regulation: the nuclear response. J Cell Mol Med. 2009;13:631-643.

46 Hammond SM: MicroRNAs as oncogenes. Curr Opin Genet Dev 1996;16:4-9.

47 Lee YS, Dutta A: MicroRNAs: small but potent oncogenes or tumor suppressors. Curr Opin Investig Drugs 2006; 7:560-564.

48 Wang Z, Luo X, Lu Y, Yang B: miRNAs at the heart of the matter. J Mol Med 2008;86:771-783.

49 Wang Z: MicroRNA interference technologies. Springer-Verlag, New York. 2009. 